\title{
The photoelectrochemical cell with hydrogen accumulation at the conditions of natural insolation
}

Ivan A. Slobodyanyuk ${ }^{\mathrm{a}}$, Igor A. Rusetskyi ${ }^{\mathrm{a} *}$, Larisa G. Shcherbakova ${ }^{\mathrm{b}}$, Michail O. Danilov ${ }^{\mathrm{a}}$, Gennadiy Ya. Kolbasov ${ }^{\mathrm{a}}$, Yuriy M. Solonin ${ }^{\mathrm{b}}$

${ }^{a}$ Vernadskii Institute of General and Inorganic Chemistry of the Ukrainian NAS, prospekt Palladina 32-34, 03680 Kyiv 142, Ukraine.

${ }^{b}$ Frantsevich Institute for Problems of Materials Science of the Ukrainian NAS, Krzhizhanovsky str., 3, 03680, Kyiv-142, Ukraine.

r2igor71@ukr.net

Keywords: photoelectrochemical cell, hydrogen accumulation, CdSe photoanodes, graphene oxide, metal hydrides.

The film photoanodes based on $\mathrm{CdSe}$ and $\mathrm{NT}-\mathrm{TiO}_{2} / \mathrm{CdSe}$ have been formed by the electrochemical and painting methods. It is shown that the introduction of graphene oxide into the structure of the semiconductor CdSe film promotes absorption of light and leads to improvement in their characteristics by 25-30\%. The compatibility of the cathode based on composite of hydrogensorbing intermetallic alloys $\mathrm{LaNi}_{4.5} \mathrm{Mn}_{0.5}+\mathrm{LaNi}_{3.5} \mathrm{Al}_{0.7} \mathrm{Mn}_{0.8}$ with current-conductive additives in pair with the CdSe photoanode is shown. It was found that $95-98 \%$ of the total current generated under the influence of sunlight at the anodes was used on the formation and accumulation of hydrogen by cathodes.

\section{Introduction}

One of the promising ways of obtaining hydrogen is the photoelectrochemical (PEC) decomposition of water under the influence of sunlight. Hydrogen produced by the PEC method is very pure and does not require additional purification for its use. The high voltage required for the decomposition of water $(1.23 \mathrm{~V})$ together with the overvoltage at the electrodes $(\sim 1 \mathrm{~V})$ necessitates the use of photoanodes with a band gap close to $2.5 \mathrm{eV}$, but such semiconductors, even theoretically, cannot provide the necessary efficiency of photoconversion because they use a small (about $4 \%$ ) area of sunlight. The use of semiconductors with a band gap of 1.3-1.7 eV, which absorbs visible light, theoretically allows several-foid increase in the efficiency of conversion of solar energy into chemical energy of hydrogen. To improve the efficiency of the production of "solar" hydrogen from water using semiconductor electrodes, two-layer and multilayer heterostructures and composites can be used. For this purpose it is possible to use a 
tandem of semiconductor photoelectrodes, which have different band gaps and variable semiconductor structures, as well as metal oxides modified by doping them with both metallic, and nonmetallic additives, etc. [1-3].

The possibility of using hydrogen sorbing cathodes (metal hydrides $(\mathrm{MH})$ ) instead of expensive metals of the Pt group to obtain and accumulate "solar" hydrogen in a photoelectrochemical system was considered in $[4,5]$, but the process of hydrogen storage was ineffective due to the use of wide-band photoanodes. Photoelectrochemical systems in which it is possible to use semiconductor anodes sensitive to the visible spectrum of sunlight [6] and cathodes that efficiently absorb hydrogen are some of the promising directions in creating systems for the production and accumulation of "solar" hydrogen.

$\mathrm{A}^{\mathrm{II}} \mathrm{B}^{\mathrm{VI}}$ compound based semiconductor electrodes were chosen as the object of research, nanocomposites and heterostructures were developed on their basis with reduced graphene oxide as well as $\mathrm{AB}_{5}$ - type ( $\mathrm{LaNi}_{5}$ - based) hydrogen - sorbing alloys for the PEC system for hydrogen production.

\section{Experimental}

The $\mathrm{TiO}_{2}\left(\mathrm{NT}-\mathrm{TiO}_{2}\right)$ nanotubes on a $\mathrm{Ti}$ substrate were obtained by the potentiostatic anodic polarization of a titanium foil in an electrolyte containing $70 \%$ of glycerol, $30 \%$ of water and 1.5 wt $\%$ of $\mathrm{NH}_{4} \mathrm{~F}$. The titanium foil was previously degreased in acetone. The process was carried out at $30 \mathrm{~V}$ for 1 hour, followed by annealing at $500{ }^{\circ} \mathrm{C}$ for 3 hours [7].

CdSe films were obtained by the painting method on a previously prepared $\mathrm{Ti}$ substrate with a surface area of $2.7 \mathrm{~cm}^{2}$. The following suspension was prepared for the deposition: $0.5 \mathrm{~g}$ of an aqueous solution of polyethylene glycol ( $1 \%$ by weight) was added to $1 \mathrm{~g}$ of $\mathrm{CdSe}$ and $0.25 \mathrm{~g}$ of $\mathrm{CdCl}_{2}$ for the $\mathrm{A} 1$ A3 photoanodes. The initial CdSe powder was milled in a ball mill with agate balls for 32 hours and then treated for 2 hours with an ultrasonic disperser UD-11 (Techpan, Poland): at an oscillator frequency of $22 \mathrm{kHz}$ and a power of 100 watts. To increase the photocatalytic activity of semiconductor films, $0.19-2.42$ wt. \%. of graphene oxide (relative to the mass of $\mathrm{CdSe}$ ) (A4 photoanode) was added to the CdSe suspension. Graphene oxide (GO) was synthesized by the oxidative destruction of multiwalled carbon nanotubes using the modified Hammers method. The method of producing GO was described in $[8,9]$. The films of CdSe were applied in 2 layers. Each layer was annealed in an air atmosphere at $535{ }^{\circ} \mathrm{C}$ for 30 minutes. According to literature, at this temperature, it is also possible to partially reduce graphene oxide by decarboxylation [10]. After that, the surface was activated in an aqueous solution of $0.5 \mathrm{M} \mathrm{CrO}_{3}$ for 45 seconds at room temperature and washed in distilled water. 
The counter-electrodes for the photoaccumulators were prepared by the several methods. The $\mathrm{Cu}_{2} \mathrm{~S}$ electrode was prepared by the immersion of the $(70 \% \mathrm{Cu}, 30 \% \mathrm{Zn})$ in a polysulfide solution. The sulfidizing process can be accelerated by brass anodizing in a polysulphide solution. The presence of zinc in the alloy ensures the mechanical strength of the electrode, as pure copper in a polysulfide solution will rapidly degrade throughout the volume to form $\mathrm{Cu}_{2} \mathrm{~S}$. At the same time, the presence of zinc in the alloy during sulfidizing limits the interaction surface. The main part of the matrix is metallic zinc, which keeps $\mathrm{Cu}_{2} \mathrm{~S}$ in the bulk. In addition to this method, the $\mathrm{Cu}_{2} \mathrm{~S}$ electrode was prepared by dipping a copperplated stainless steel mesh in a polysulfide solution. Copper gradually corrodes, forming a layer of $\mathrm{Cu}_{2} \mathrm{~S}$. The $\mathrm{CoS}$ electrodes were prepared by pressing onto a nickel mesh CoS powder with conductive acetylene black with PTFE emulsion as a binder at a pressure of $150 \mathrm{~kg} \mathrm{~cm}^{-2}$.

The cathode $(\mathrm{C} 1) 8 \mathrm{~mm}$ in diameter and $0.08 \mathrm{~g}$ in mass was produced by pressing a mixture of powders of hydrogen - sorbing alloy and copper in a 1:3 weight ratio onto a nickel mesh as current collector. The active part of the cathode was a mixture of powders of two hydrogen - sorbing alloys ( $\mathrm{LaNi}_{4.5} \mathrm{Mn}_{0.5}+$ $\mathrm{LaNi}_{3.5} \mathrm{Al}_{0.7} \mathrm{Mn}_{0.8}$ ), taken in a $1: 1$ weight ratio. The study of electrochemical activation and sorption characteristics of cathodes was conducted with a computerized potentiostathalvanostat PGSTAT 4-16. The electrodes were activated in 3-5 cycles and showed a maximum discharge capacity of $280-300 \mathrm{mAh} / \mathrm{g}$ along with good kinetics in the hydrogen back reactions [11]. The capacity of the cathodes used in the process was about $23 \mathrm{mAh}$, which is enough for several hours of work in together with the photoanode. The amount of hydrogen absorbed by the cathode during photoelectrochemical charge in the PEC cell was calculated from discharge curves.

A polymethylmethacrylate cell with the cathode and anode chambers separated by an ion-exchange membrane MF-4SK with a builtin cathode chamber mercury-oxide reference electrode was used for the studies $[12,13]$. The photoelectrodes were placed in the anode chamber filled with an alkaline solution of sulphide $\left(1 \mathrm{M} \mathrm{KOH}+1 \mathrm{M} \mathrm{Na} \mathrm{Na}_{2} \mathrm{~S}\right)$ or sodium polysulphide $(1 \mathrm{M} \mathrm{KOH}+1 \mathrm{M} \mathrm{Na} 2 \mathrm{~S}+1 \mathrm{M} \mathrm{S})$. Sulfide electrolyte was used to exclude the effect of light absorption on the characteristics of photoelectrodes, and during the operation of photoelectrodes this solution was enriched with polysulfide ions [14]. The cathode chamber of the hydrogen - sorbing electrode was filled with a $30 \% \mathrm{KOH}$ solution (Figure 1).

To track the displacement of the Sun and to achieve the maximum efficiency of solar cells, a sun tracker was used (Figure 1). 


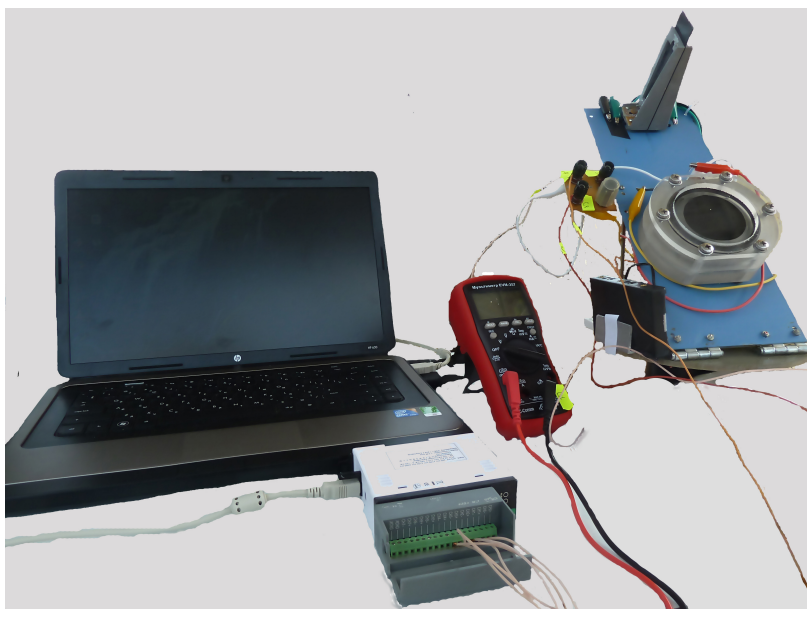

Figure 1. Photoelectrochemical equipment for hydrogen production.

The tracker consists of two photoresistor sensors, a controller (Arduino), and a movable platform with a servo - drive. The photoelectrochemical cell is placed on the platform. The system automatically measures and records data using a USB - 2019 data logger, as well as a BM 251 digital multimeter.

\section{Results and discussion}

Under laboratory conditions, it was found that the formation of a $\mathrm{TiO}_{2}$ nanotube layer leads to an increase in the efficiency of charge carrier accumulation on $\mathrm{NT}-\mathrm{TiO}_{2} / \mathrm{CdSe}$ electrodes due to an increase in the potential of flat bands, which determines the magnitude of the electric field at the surface of the semiconductor and affects the separation rate of photogenerated carriers, thereby reducing recombination in the space charge region [15]. The value of the dark cathode current measured on the resulting photoelectrodes in the polysulfide electrolyte did not exceed $5 \times 10^{-6}$ $\mathrm{A} / \mathrm{cm}^{2}$.

It has been established that the incorporation of reduced graphene oxide into NT- $\mathrm{TiO}_{2} / \mathrm{CdSe}$ composite promotes the absorption of light and leads to an improvement of its characteristics by $25-30 \%$ due to a better separation of electron-hole pairs and, as a consequence to, a decrease in the loss of photogenerated charge carriers on recombination. The optimal amount of graphene oxide as a modifier is $1.16 \%$ by mass, at which the maximum $\mathrm{V}_{\mathrm{im}}$ was about $0.6 \mathrm{~V}$ and $\mathrm{I}_{\mathrm{sc}}$ was about $6 \mathrm{~mA} / \mathrm{cm}^{2}[16]$.

The tests of photoanodes were conducted by different methods of forming a photosensitive semiconductor layer, which operates together with the $\mathrm{MH}$ cathode.

In an open circuit in a sulfide solution, the potentials of the anodes A1 and A4 had values of $-1.23 \mathrm{~V}$ and $-1.24 \mathrm{~V}$, for the cathodes in a $30 \%$ solution of $\mathrm{KOH}$, the potentials were about $-0.91 \div-0.93 \mathrm{~V}$. Under the conditions of stable solar illumination, the potentials of both electrodes reach relatively stable values. The anode A4 containing the GO operates together with the cathode in the region of the more negative potentials $(-1.10 \mathrm{~V})$ than the anode without the addition of GO $(\mathrm{E}=-1.08 \mathrm{~V})$. When operating together with the anode A4, the cathode is also charged in the region of more negative potentials. 
When illuminated with solar light, the photonodes A1 - A3 generate currents, which remain stable at the constant light flux during operation in a PEC cell (Figure 2).

Despite the same composition of photoanodes and close values of light flux intensity, the value of photocurrents is somewhat different and is about $3-4 \mathrm{~mA}$. At the photoanode A4 under identical conditions, 25-30\% higner currents are generated (from $3.7 \mathrm{~mA}$ to $5.0 \mathrm{~mA}$ ). It has been established that with increase in the number of painting layers of CdSe (3 layers), the magnitude of photocurrents and the nature of their change during cell operation do not practically change. Under laboratory conditions, it was found that on a composite anode consisting of an electrochemical layer and 2 painting layers of CdSe, the photocurrent has the greatest value among all the studied samples.

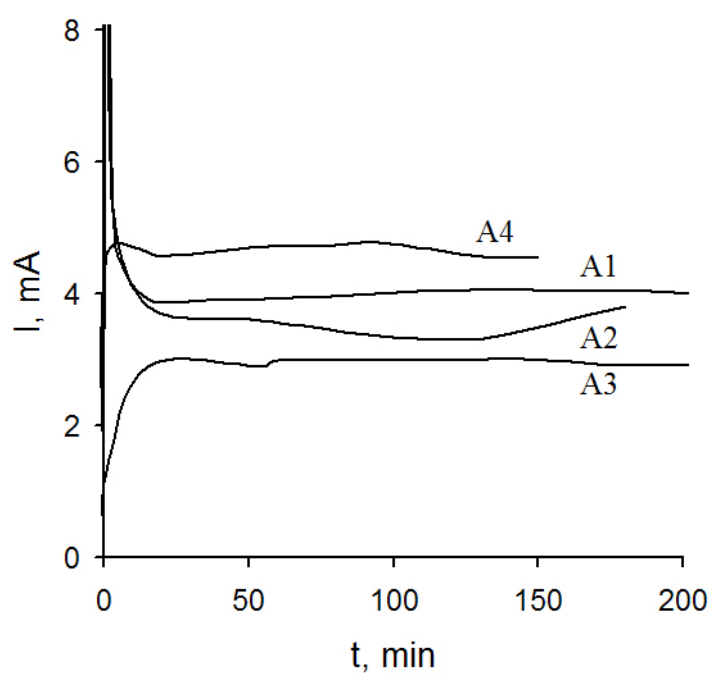

Figure 2. Time dependence of photocurrent under solar illumination, which is generated at different photoanodes (A1-A4), working together with the cathode $\mathrm{C} 1$ in a PEC cell.
The influence of the composition of the solution (sulfide and sodium polysulphide) on the characteristics of the photoanodes A1 and A4 has been studied. From the obtained data it follows that the potentials of the anode with the addition of GO (A4) when operating in a PEC cell have the same value regardless of the composition of the solution (Figure 3). At the same time, when the anode A1 operates in a polysulphide solution, its potential is shifted to the anodic region.

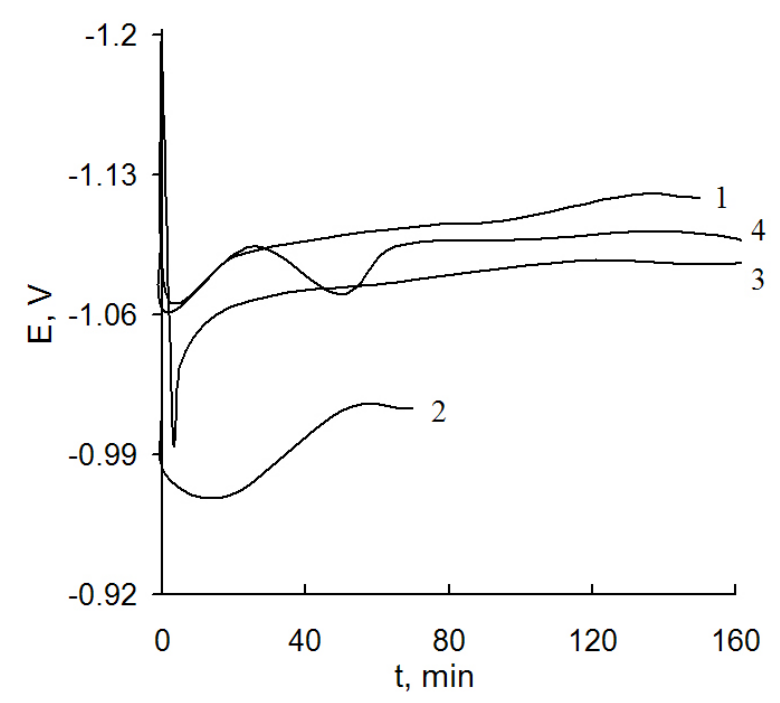

Figure 3. Variation of the potential $E$ of the anodes A1 $(3,2)$ and $\mathrm{A} 4(1,4)$ as a functional of time $t$ during operation together with the cathode $\mathrm{C} 1$ in a PEC cell in a solution of sulfide $(1,3)$ and sodium polysulphide $(2,4)$.

Changes in currents generated at the anodes A1 and A4 under illumination by sunlight when working in solutions of sulfide and sodium polysulphide are shown in Figure 4. It is seen that during the operation of the photoanode A4 in a polysulfide solution, the 
photocurrent decreases from $4.8 \mathrm{~mA}$ to 2.93 has been established that in the same mA.

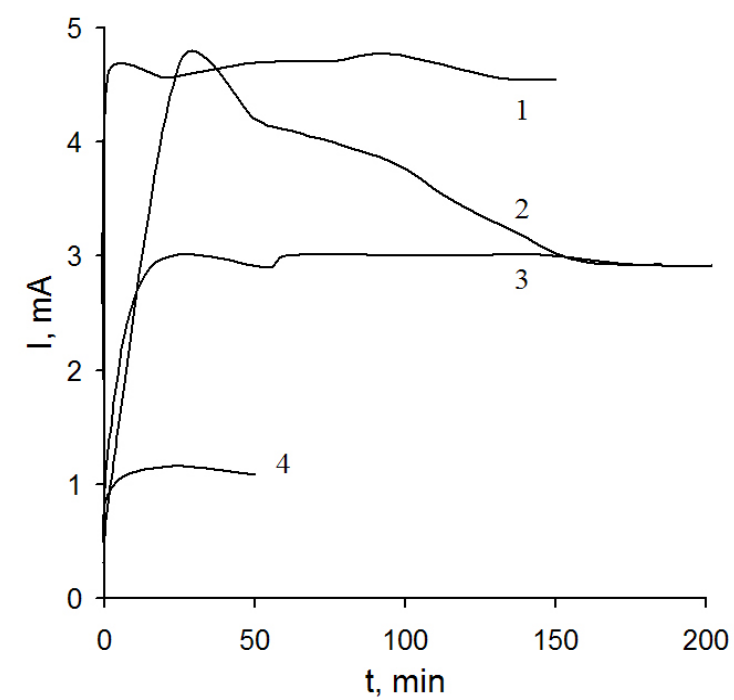

Figure 4. Variation of the photocurrent $I$ at the anodes A4 $(1,2)$ and A1 $(3,4)$ as a functional of time $t$ during operation together with the cathode $\mathrm{C} 1$ in a PEC cell in a solution of sulfide $(1,3)$ and sodium polysulphide $(2,4)$. technologies for the production of CdSe layers with and without the addition of GO, light conversion is more efficient on electrodes with smaller area.

The discharge of the cathode by a current of $4 \mathrm{~mA}$ after a charge in a PEC cell has shown that $90 \%$ to $98 \%$ of the current generated at the photoanode is used for the accumulation of hydrogen by the cathode. The overall efficiency of the PEC is limited only by the efficiency of the semiconductor photoanode.

The results of the study of the PEC cell operation are given in Table 1.

When the photoanode A1 operates in a polysulfide solution, stable photocurrents are generated, but they are $\sim 3$ times lower $(\sim 1 \mathrm{~mA})$ than in a solution of sodium sulfide.

Similar te sts were carried out on photoanodes with an area of about $20 \mathrm{~cm}^{2}$. It

Table 1. Test data of the PEC cell for the hydrogen accumulation.

\begin{tabular}{|c|c|c|c|c|c|c|}
\hline \multirow{2}{*}{\multicolumn{2}{|c|}{ Electrodes }} & \multicolumn{4}{|c|}{ Characteristics of PEC cell } & \multirow{3}{*}{$\begin{array}{c}\text { Light power**, } \\
\mathrm{mW} / \mathrm{cm}^{2}\end{array}$} \\
\hline & & \multirow[t]{2}{*}{$\begin{array}{c}\text { Ratio } \\
\mathrm{S}_{\text {an }} / \mathrm{S}_{\text {cath }}\end{array}$} & \multirow[t]{2}{*}{$\begin{array}{c}\text { Photo- } \\
\text { current*, mA }\end{array}$} & \multicolumn{2}{|c|}{$\begin{array}{c}\text { Current density, } \\
\mathrm{mA} / \mathrm{cm}^{2}\end{array}$} & \\
\hline anode & cathode & & & anode & cathode & \\
\hline A1 & $\mathrm{C} 1$ & 2.7 & 4.2 & 1.400 & 4.2 & 79.2 \\
\hline $\mathrm{A} 2$ & & & 3.7 & 1.233 & 3.7 & 76.0 \\
\hline
\end{tabular}




\begin{tabular}{|c|c|c|c|c|}
\hline A3 & 3.0 & 1.000 & 3.0 & 77.2 \\
\hline A4 & 5.0 & 1.667 & 5.0 & 75.8 \\
\hline
\end{tabular}

* maximum current magnitude.

** solar flux intensity, which corresponds to the maximum value of photocurrent.

\section{Conclusions}

Using the electrochemical and painting methods with subseqnent annealing, photosensitive film photoanodes based on $\mathrm{CdSe}$ and $\mathrm{NT}-\mathrm{TiO}_{2} / \mathrm{CdSe}$ have been formed. It has been established that the introduction of graphene oxide into the structure of semiconductor CdSe film leads to an improvement of its characteristics by $25-30$ $\%$.

It has been shown that the composite cathode based on hydrogen-sorbing intermetallic alloys $\mathrm{LaNi}_{4.5} \mathrm{Mn}_{0.5}+\mathrm{LaNi}_{3.5} \mathrm{Al}_{0.7} \mathrm{Mn}_{0.8}$ with currentconducting additives is compatible with the CdSe photoanode. It has been established that on cathode materials at currents of $\leq 5 \mathrm{~mA} / \mathrm{cm}^{2}$, negative potentials relative to the equilibrium potential of hydride formation occur. It has been found that $95-98 \%$ of the current generated by sunlight at anodes is spent on the formation and accumulation of hydrogen on cathodes.

\section{References}

[1] Bak T, Nowotny J, Rekas M and et.al. Photoelectrochemical hydrogen generation from water using solar energy. Materials-related aspects. International J. Hydrogen Energy 2002;27(10):985-1111.

[2] Miller EL, Paluselli D, Marsen B and et.al. Development of reactively sputtered metal oxide films for hydrogen-producing hybrid multijunction photoelectrodes. Sol. Energ. Mat. Sol. Cells 2005;88(2):131-144.

[3] Fujishima A, Zhang $X$, Tryk DA. Heterogeneous photocatalysis: From water photolysis to applications in environmental cleanup. International J. Hydrogen Energy 2007;32(14):2664-2672.

[4] Wang GT, Tu JP, Wang XL and et.al. Photochargeability of $\mathrm{SrTiO}_{3} / \mathrm{Ni} /$ hydrogenSrTiO$/ 2 / \mathrm{Ni} /$ hydrogen storage alloy electrode in $\mathrm{KOH}$ solution. International J. Hydrogen Energy 2007;32(15):3586-3591.

[5] Akuto K, Sakurai Y. A photorechargeable metal hydride/air battery. J. Electrochem. Soc 2001;148(2):A121-A125.

[6] Clark WDK, Hull MN, Arms JT, inventors; The International Nickel Co., Inc., assignee. Photoelectrochemical cell with in-situ storage using hydrogen storage electrodes. United States patent 4259418. 1981 march 31.

[7] Macak JM, Hildebrand H, Marten-Jahns U, Schmuki P. Mechanistic aspects and growth of large diameter self-organized $\mathrm{TiO}_{2}$ nanotubes. J. Electroanal. Chem 2008;621(2):254-266.

[8] Danilov MO, Slobodyanyuk IA, Rusetskii IA et al. Reduced graphene oxide: a promising 
electrode material for oxygen electrodes. J. Nanostruct.

Chem 2013;3:49.

[9] Danilov MO, Slobodyanyuk IA, Rusetskii IA, Kolbasov GYa. Synthesis of Reduced Graphene Oxide Obtained from Multiwalled Carbon Nanotubes and Its Electrocatalytic Properties. In: Aliofkhazraei M, Ali N, Milne WI, Ozkan CS, Mitura S, Gervasoni JL, editor. Graphene Science Handbook: Fabrication Methods. New York: CRC Press Taylor \& Francis Group; 2016. p. 205-226.

[10] Shcherbakova LG, Solonin YuM, Muratov VB. Scientific and technical foundations of creating the cathodes for photoelectrochemical system of "sunny". Paper presented at: IGEC-8 2013. Proceedings of the Hydrogen Accumulation of 8-th International Green Energy Conference; 2013 June 17-19; Kiev, Ukraine, pp. 424-430.

[11] Mikhailov S. Physics and Applications of Graphene - Experiments. Croatia: InTech; 2011, p. 540.

[12] Solonin YuM, Kolbasov GYa, Rusetskii IA, et al. Hydrogen Storage in Metal Hydride Under Action of Sunlight. Paper presented at: Fuel Cell Technologies: State and Perspectives 2004. Proceedings of the NATO Advanced Research Workshop on Fuel Cell Technologies: State And Perspectives; 2004 June 6 -10; Kyiv, Ukraine. Dordrecht: Springer; 2005. p. 193-198.

[13] Shcherbakova L.G., Dan`ko D.B., Muratov V.B. et al. Metal hydride use for solar energy accumulation. Paper presented at: ICHMS 2005. Proceedings of the NATO Advanced Research Workshop on Hydrogen Materials Science and Chemistry of Carbon Nanomaterials; 2005 September 5-11; Sevastopol, Crimea, Ukraine. Dordrecht: Springer; 2007. pp. 699-706.

[14] Bratsch SG. Standard electrode potentials and temperature coefficients in water at 298.15 K. J. Phys. Chem 1989;18:1-21.

[15] Pleskov YuV, Gurevich YuYa. Semiconductor Photoelectrochemistry. New York: Springer; 1986, p. 422.
[16] Rusetskii IA, Slobodyanyuk IA, Danilov MO, Kolbasov GYa. Photosensitive nanocomposites based on nanotubes $\mathrm{TiO}_{2}, \mathrm{CdSe}$ and graphene oxide. Him. Fiz. Tehnol. Poverhni 2016; 7(2):195-201. 